\title{
The brain-in-motion study: effect of a 6-month aerobic exercise intervention on cerebrovascular regulation and cognitive function in older adults
}

Amanda V Tyndall 1,2, Margie H Davenport 1,2, Ben J Wilson³ , Grazyna M Burek¹,2, Genevieve Arsenault-Lapierre ${ }^{1,2,4}$, Eryka Haley ${ }^{1,2}$, Gail A Eskes ${ }^{1,5,6,7}$, Christine M Friedenreich $8,9,10,11$, Michael D Hill 2,3,4,10,12, David B Hogan 2,3,4,10,13, R Stewart Longman ${ }^{2,14}$, Todd J Anderson ${ }^{15,16}$, Richard Leigh 1,3,17,18, Eric E Smith 2,4,10,12 and Marc J Poulin 1,2,4,11,15*

\begin{abstract}
Background: Aging and physical inactivity are associated with declines in some cognitive domains and cerebrovascular function, as well as an elevated risk of cerebrovascular disease and other morbidities. With the increase in the number of sedentary older Canadians, promoting healthy brain aging is becoming an increasingly important population health issue. Emerging research suggests that higher levels of physical fitness at any age are associated with better cognitive functioning and this may be mediated, at least in part, by improvements in cerebrovascular reserve. We are currently conducting a study to determine: if a structured 6-month aerobic exercise program is associated with improvements or maintenance of both cerebrovascular function and cognitive abilities in older individuals; and, the extent to which any changes seen persist 6 months after the completion of the structured exercise program.

Methods/design: Two hundred and fifty men and women aged 55-80 years are being enrolled into an 18-month combined quasi-experimental and prospective cohort study. Participants are eligible for enrollment into the study if they are inactive (i.e., not participating in regular physical activity), non-smokers, have a body mass index $<35.0 \mathrm{~kg} /$ $\mathrm{m}^{2}$, are free of significant cognitive impairment (defined as a Montreal Cognitive Assessment score of 24 or more), and do not have clinically significant cardiovascular, cerebrovascular disease, or chronic obstructive pulmonary airway disease. Repeated measurements are done during three sequential six-month phases: 1) pre-intervention; 2) aerobic exercise intervention; and 3) post-intervention. These outcomes include: cardiorespiratory fitness, resting cerebral blood flow, cerebrovascular reserve, and cognitive function.

Discussion: This is the first study to our knowledge that will examine contemporaneously the effect of an exercise intervention on both cerebrovascular reserve and cognition in an older population. This study will further our understanding of whether cerebrovascular mechanisms might explain how exercise promotes healthy brain aging. In addition our study will address the potential of increasing physical activity to prevent age-associated cognitive decline.
\end{abstract}

Keywords: Physical fitness, Cerebrovascular function, Cognition, Aging

\footnotetext{
*Correspondence: poulin@ucalgary.ca

'Department of Physiology \& Pharmacology, Faculty of Medicine, University

of Calgary, Calgary, Alberta T2N 4N1, Canada

${ }^{2}$ Hotchkiss Brain Institute, Faculty of Medicine, University of Calgary, Calgary,

Alberta T2N 4N1, Canada

Full list of author information is available at the end of the article
}

\section{Biomed Central}

(c) 2013 Tyndall et al.; licensee BioMed Central Ltd. This is an Open Access article distributed under the terms of the Creative Commons Attribution License (http://creativecommons.org/licenses/by/2.0), which permits unrestricted use, distribution, and reproduction in any medium, provided the original work is properly cited. 


\section{Background}

Aging is associated with declines in certain cognitive domains and lower levels of physical activity [1,2]. The Public Health Agency of Canada [2] and World Health Organization [3] report that adults between 65 and 74 years of age are the most sedentary portion of the population. An estimated $60 \%$ of older adults lead sedentary lifestyles and do not engage in enough physical activity to achieve favorable health benefits [4]. Physical inactivity is a recognized modifiable risk factor of cerebrovascular disease and the cognitive decline seen in older adults $[5,6]$. With the projected doubling of the number of older Canadians over the next 25 years [7], it is anticipated that the personal and societal burden of age-associated conditions like cerebrovascular disease and dementia (e.g., Alzheimer's disease, AD) will increase substantially [8].

Post-maturational aging is associated with reduced abilities in a number of cognitive processes, including attention, learning and memory, and executive control [9]. These age-related changes, while detectable, are generally considered part of the aging process and usually do not interfere with the ability to live independently. Dementia, an acquired decline in multiple cognitive areas causing a significant impairment in social or occupational functioning, occurs in approximately $8 \%$ in the older population, with $\mathrm{AD}$ and vascular dementia $(\mathrm{VaD})$ either alone or in combination the most common causes $[10,11]$. As both aging and vascular disease are risk factors for both $\mathrm{AD}$ and $\mathrm{VaD}$, age-associated declines in cerebrovascular function might contribute to the development of these disorders [11-13].

With normal aging there is an approximately 5\% decrease per decade in resting cerebral blood flow (CBF) [14]. Although the brain represents 2.0 to $2.3 \%$ of an adult's total body weight, in percentage terms it accounts for ten times more of the body's total resting energy consumption $[15,16]$. Since cerebral tissue does not produce or store sources of energy, its high metabolic need requires constant and adequate blood supply. Agerelated hypoperfusion may be associated with sufficient reductions in the delivery of oxygen and nutrients and inadequate removal of metabolic by-products to produce impaired cognitive function and slowly progressive cellular injury [17]. Neurons, glial and vascular cells are linked together in neurovascular units where neuronal and glial signals control local CBF [17-19]. With aging, neurovascular coupling is disrupted, which could result in the metabolic requirements of the brain tissue not being matched by CBF $[15,18]$. Decreases in CBF have been associated with a number of age-related neurodegenerative changes including a loss of neuropil (i.e., synaptically dense regions of the nervous system mainly composed of unmyelinated axons, dendrites and glial processes) [20].
There is consistent evidence that regular exercise promotes brain health and is associated with a lower risk for age-related cognitive decline and dementia [21], however the underlying mechanisms have not been well defined [22]. Neuroimaging studies of older adults indicate that higher levels of cardiovascular fitness are associated with larger volumes of specific brain regions including the hippocampus, an important region for learning and memory [23,24]. This effect may be attributable, in part, to neurogenesis [25] possibly mediated by increases in vascularization, elevated levels of neurotrophins and growth factors, and/or improved neuronal survival in the aging brain [26].

Previous studies have focused primarily on neuronal processes that may explain why physical activity promotes healthy brain aging while cerebrovascular mechanisms that might underlie improved cognitive function are relatively poorly understood. Pharmacological manipulation of cerebral blood flow can modify performance on a variety of cognitive tasks in both animal models and humans (for review see $[15,27]$ ). Cerebrovascular networks are thought to have a high degree of plasticity (i.e., they are changeable or modifiable) [27]. Exercise appears to stimulate the growth of new capillaries from preexisting vessels in the brain and improve resting $\mathrm{CBF}[27,28]$. We recently demonstrated that increased levels of physical fitness were associated with greater cerebrovascular reserve (i.e., the ability of cerebral arteries to dilate in response to a stimulus) and improved cognitive function [12]. These data suggest that the link between physical fitness and cognition may be mediated, at least in part, by improvements in cerebrovascular function.

We are conducting a quasi-experimental prospective cohort study with two primary aims: 1 ) to determine the effect of a six-month aerobic exercise intervention on physical fitness, resting CBF, cerebrovascular reserve, and cognitive function in 250 sedentary men and women between the ages of 55 and 80 years; and, 2) to determine the extent to which the changes in cerebrovascular and cognitive function persist six months following the completion of the exercise intervention. We hypothesize the improvement in cognitive function derived from regular aerobic exercise is at least partially mediated by enhanced cerebrovascular reserve. Further, we hypothesize that these beneficial changes will persist in participants who remain physically active as compared to those who revert to a sedentary lifestyle. The purpose of this manuscript is to describe the study design and research methodologies in detail.

\section{Methods}

The Brain in Motion (BIM) study is an 18-month combined quasi-experimental and prospective cohort study 
consisting of three six-month phases: 1) pre-intervention phase; 2) aerobic exercise intervention phase; and 3) postintervention (Figure 1).

\section{Participant recruitment}

The target population for enrollment is sedentary men and women aged 55-80 years. Participants are being recruited through media, poster and newspaper advertisements. Potential participants must provide informed written consent prior to enrollment into the study. Participants are also invited to provide separate written consent for genetic testing (see section on Blood Sampling and Biomarker Assessments). The study protocol was approved by the University of Calgary Conjoint Health Research Ethics Board.

\section{Inclusion/exclusion criteria}

During an initial phone interview, interested participants are assessed for their eligibility based on pre-determined inclusion and exclusion criteria (Table 1). Potential participants who successfully complete an initial telephonebased evaluation are then scheduled for a 60-minute on-site assessment of eligibility (Table 1).

\section{Study design}

The BIM study design and timeline is outlined in Figure 1. A second baseline measure allows an estimate of practice effects on the cognitive test performance and an estimate of the consistency of our other various measures. Additionally, this second assessment ensures feasibility of the testing in the selected study population and that participants will comply with follow-up testing prior to the exercise intervention.

\section{Pre-intervention baseline phase test $1 \mathrm{~A}$ (month 0 )}

The baseline assessment during the pre-intervention phase is conducted during four separate on-site appointments during which the following are done: 1) fasting blood work; 2) incremental treadmill test to assess maximal aerobic capacity $\left(\mathrm{VO}_{2} \mathrm{max}\right) ; 3$ ) assessment of cerebrovascular function; and 4) assessment of cognitive function, mood and sleep (Table 2). In addition, participants are required to fill out a Dietary History Questionnaire based on their intake over the previous 12 months [30]. Details of these evaluations are given later.

\section{Pre-intervention baseline phase test 1B (month 6)}

Six months following enrollment into the study, and immediately prior to the exercise intervention phase,

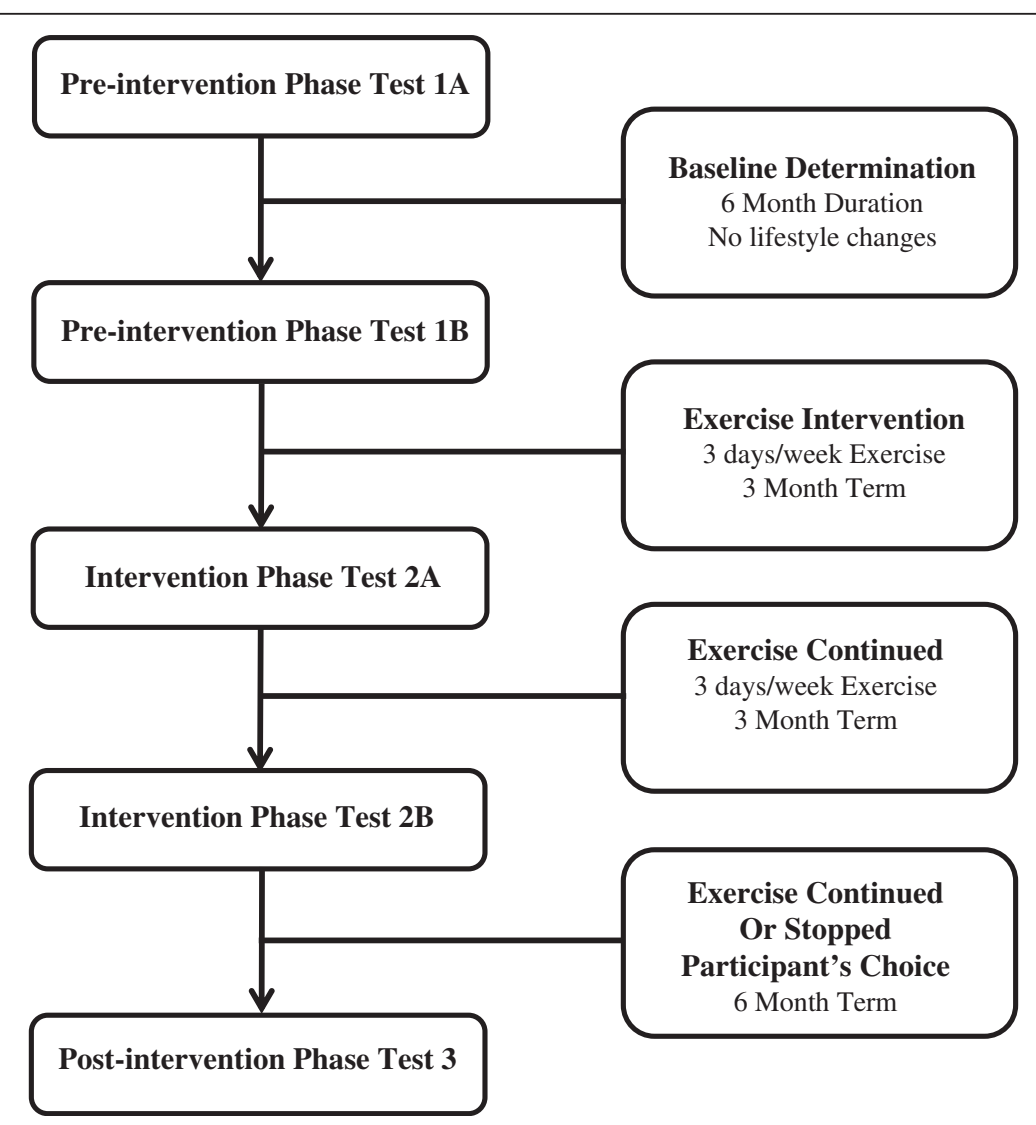

Figure 1 Flow chart of the phases of the BIM study. 
Table 1 Inclusion criteria - participant must fulfill all criteria to be admitted to the study

\begin{tabular}{|c|c|}
\hline Assessment phase & Criteria \\
\hline \multirow[t]{8}{*}{ Telephone interview } & $\begin{array}{l}\text { Participant engages in less than } 30 \text { minutes of moderate exercise four days per week or } 20 \text { continuous minutes } \\
\text { of vigorous exercise two days per week }\end{array}$ \\
\hline & Participant has a body mass index (BMI) of less than $35 \mathrm{~kg} / \mathrm{m}^{2}$ \\
\hline & Participant is able to walk independently outside and up and down at least 20 stairs \\
\hline & $\begin{array}{l}\text { Participant has not been diagnosed with an active cardiovascular/cerebrovascular disease or obstructive } \\
\text { airway disease that would preclude their ability to safely exercise }\end{array}$ \\
\hline & Participant has been a non-smoker for at least 12 months \\
\hline & Participant has not had major surgery or trauma in the last six months \\
\hline & Participant is free of debilitating neurological disorders (e.g., Multiple Sclerosis and AD) \\
\hline & Participant has written permission from their attending physician to participate in the study \\
\hline \multirow[t]{2}{*}{ On-site assessment } & Montreal Cognitive Assessment (MoCA) score $\geq 24$ [29] \\
\hline & $\begin{array}{l}\text { History (i.e., cardiovascular, respiratory, hepatic, endocrine, neurological, endocrine, and musculoskeletal health) } \\
\text { and physical examination by a study physician to assess safety/appropriateness for exercise. Current medications } \\
\text { (i.e., prescribed, over-the-counter, and complementary agents), allergies, and/or history of any substance abuse issues }\end{array}$ \\
\hline
\end{tabular}

participants undergo the same evaluations as done during Pre-Intervention Baseline Phase Test 1A (see Table 2 for details). At an additional visit, the Lifetime Physical Activity Questionnaire [31] is administered by study personnel.

\section{Exercise intervention phase (months 6-12)}

Participants then take part in the supervised six-month aerobic training program that is held three days per week at the Fitness Centre in the Faculty of Kinesiology at the University of Calgary. Each exercise session includes a fiveminute warm up, aerobic exercise, a five-minute cool down,

Table 2 Table of testing and questionnaires at each phase

\begin{tabular}{|c|c|c|c|c|c|}
\hline & \multicolumn{5}{|c|}{ Time (months) } \\
\hline & 0 & 6 & 9 & 12 & 18 \\
\hline \multicolumn{6}{|c|}{ Phase } \\
\hline Tests & $1 \mathrm{~A}$ & $1 \mathrm{~B}$ & $2 \mathrm{~A}$ & $2 B$ & 3 \\
\hline Blood work & $\checkmark$ & $\checkmark$ & $\checkmark$ & $\checkmark$ & $\checkmark$ \\
\hline Genetics & $\checkmark$ & & & & \\
\hline Maximal aerobic capacity & $\checkmark$ & $\checkmark$ & $\checkmark$ & $\checkmark$ & $\checkmark$ \\
\hline Cerebrovascular function & $\checkmark$ & $\checkmark$ & $\checkmark$ & $\checkmark$ & $\checkmark$ \\
\hline Cognitive function & $\checkmark$ & $\checkmark$ & & $\checkmark$ & $\checkmark$ \\
\hline \multicolumn{6}{|l|}{ Questionnaires } \\
\hline Mood & $\checkmark$ & $\checkmark$ & $\checkmark$ & $\checkmark$ & $\checkmark$ \\
\hline Sleep & $\checkmark$ & $\checkmark$ & $\checkmark$ & $\checkmark$ & $\checkmark$ \\
\hline Lifetime physical activity & & $\checkmark$ & & & \\
\hline Past year physical activity & & & & $\checkmark$ & \\
\hline Past six month physical activity & & & & & $\checkmark$ \\
\hline Diet History & $\checkmark$ & & & $\checkmark$ & \\
\hline Social Support & & & & $\checkmark$ & \\
\hline
\end{tabular}

and stretching. Exercise prescriptions follow American College of Sports Medicine guidelines [32]. As participants progress through the exercise intervention, the duration of aerobic exercise (in addition to warm up and cool down) increases from 20 to 40 minutes. Exercise intensity is determined based on individual $\mathrm{VO}_{2}$ max. The intensity builds from $30-45 \%$ until $60-70 \%$ maximum heart rate reserve (HRR) is achieved. Participants wear a Polar $^{\circledR}$ heart rate monitor at each session to ensure compliance to their target heart rate zones. Heart rate data are collected and stored during each exercise session and are then exported offline following the exercise session to analyze heart rates during the exercise session (Polar ${ }^{\circledR}$ Team $^{2}$ system). Participants are considered compliant if they attend at least $85 \%$ of the total exercise sessions. If an exercise session is missed, participants are strongly encouraged to "make-up" the session independently and record the unsupervised exercise session in a personal workout logbook. In addition to "make-up" exercise sessions, participants are also required to record any additional independent unsupervised exercise sessions.

\section{Intervention phase test $2 A$ (month 9)}

Midway (3 months) through the exercise program, participants undergo repeat testing (same evaluations done during Phase Test 1A/1B (see Table 2 for details)) to assess for changes in parameters over time. Based on their results, exercise prescriptions for participants may be adjusted. In addition, sleep and mood are assessed by self-report questionnaires.

\section{Exercise intervention phase test $2 B$ (month 12)}

Repeat testing is again done at the end of the 6-month intervention (see Table 2 for details). The Dietary History Questionnaire [28] and a Past Year Physical 
Activity Questionnaire [33] (details given later) are selfadministered questionnaires completed at this time point.

\section{Post-intervention phase test 3 (month 18)}

Six-months following the completion of the exercise intervention, participants are re-evaluated (see Table 2 for details). During this six-month period, participants independently decide whether or not they continue with an exercise program. A Past Six-Month Physical Activity Questionnaire [33] is completed by participants to determine the amount of physical activity they engaged in following the completion of the supervised exercise sessions. This questionnaire permits a categorization of participants by their activity levels to help assess the extent to which changes in cerebrovascular and cognitive function are maintained six-months following the exercise intervention.

\section{Blood sampling and biomarker assessments}

Fasted venous blood samples are collected five times from each participant as shown in Figure 1. Sex steroid hormone status (estradiol, progesterone, testosterone, sex hormone binding globulin), lipids (cholesterol, high and low density lipoprotein, triglycerides), hematology (complete blood count), thyroid (thyroid stimulating hormone), renal (creatinine), hepatic (alanine aminotransferase and bilirubin), and markers of vascular function influenced by age and physical fitness [34] (i.e., oxidative and nitrative stress, antioxidant enzyme capacity, and products of nitric oxide metabolism) are being measured.

For participants who provide consent for genetic testing, blood samples are also collected for this purpose. This testing will include catechol-O-methyl-transferase, brain-derived neurotropic factor, and apolipoprotein $\mathrm{E}$ \&4 genotyping, which have previously been shown to influence cognitive performance [35-37]. In addition, vascular endothelial growth factor genotyping, which can be influenced by exercise presumably via vascularmediated mechanisms, will also be done [38].

\section{Maximal aerobic capacity and anthropometric measurements}

All participants undergo assessments of fitness level by a maximal aerobic capacity $\left(\mathrm{VO}_{2} \mathrm{max}\right)$ test and anthropometric measurements during each phase. Participants are instructed to refrain from vigorous exercise the day of testing, ingesting caffeine and/or alcohol six hours prior to testing and eating a heavy meal four hours prior to testing. Anthropometric measurements include height, weight, circumference measurements (waist and hip), body composition (bioelectrical impedance analysis), and grip strength. The $\mathrm{VO}_{2}$ max test is conducted on a motorized treadmill and follows the Bruce protocol [39]. A plateau in oxygen uptake with increasing work rate is observed $(<2 \mathrm{~mL} / \mathrm{kg} / \mathrm{min})$, a respiratory exchange ratio (RER) of at least 1.15, and age-predicted maximal heart rate (210-(age X 0.65)) are used as criteria for stopping the test (as recommended by the Canadian Society for Exercise Physiology (CSEP) [40] and American Thoracic Society (ATS) [41]). Outcome measures for the $\mathrm{VO}_{2}$ max test include oxygen uptake, carbon dioxide production, ventilation (tidal volume and breathing frequency), rating of perceived exertion (Borg scale), continuous heart rate recordings (12-lead electrocardiogram (ECG)), and systemic blood pressure.

This fitness test determines each study participant's maximal aerobic capacity that is used to determine work rates for the submaximal exercise test (during the cerebrovascular function test) and the target heart rate zones for the exercise intervention.

\section{Cerebrovascular function}

Cerebrovascular response to carbon dioxide and submaximal exercise is assessed in participants who have refrained from exercising the day of the test and eating or drinking anything other than water, two hours prior to testing. A capillary blood sample is taken from the middle finger and immediately analyzed for $\mathrm{PO}_{2}$ and $\mathrm{PCO}_{2}$, acid/base status, glucose, hematocrit, potassium, sodium, chloride, and calcium levels (Radiometer ABL 800, Denmark). Participants sit quietly in a chair while they are fitted with monitoring equipment. In order to noninvasively measure the $\mathrm{CBF}$ of the middle cerebral artery (MCA), a 2-MHz transcranial Doppler ultrasound (TCD) is used (Toc Neurovision ${ }^{\mathrm{TM}}$, Multigon Industries, Inc., Yonkers, NY) [42]. To locate the MCA, the TCD probe is placed in the temporal region just above the end of the zygomatic process close to the ear, using techniques previously described [42]. Maximum peak velocity $(\bar{V} P)$, intensity-weighted mean $(\bar{V} I W M)$, an index of the crosssectional area of the vessel called power $(\bar{P})$, cerebrovascular conductance, and cerebrovascular reserve are recorded as previously described [12]. Outcome measures for this test include continuous TCD recordings, heart rate (3-lead ECG; Micromon 7142 B, Kontron Medical, Milton Keynes, UK), blood pressure (beat-by-beat using finger pulse photoplethysmography, Finometer, Finapres Medical Systems, Amsterdam, The Netherlands), and arterial hemoglobin saturation (finger pulse oximetry; 3900p, Datex-Ohmeda, Madison, WI, USA).

We have previously developed and tested the protocol for this test [12]. In short, baseline end-tidal respiratory measures $\left(\mathrm{PCO}_{2}\right.$ and $\left.\mathrm{PO}_{2}\right)$ are recorded using dedicated software (Chamber, University Laboratory of Physiology, Oxford, UK), during a 10-minute baseline period. With their nose occluded, each participant breathes through a mouthpiece connected to a fine capillary that is connected 
to a mass spectrometer (AMIS 2000, Innovision, Odense, Denmark) in which end-tidal respiratory measures $\left(\mathrm{PCO}_{2}\right.$ and $\mathrm{PO}_{2}$ ) are analyzed. These end-tidal gases are averaged over the 10 minutes, and are used to determine the desired end-tidal pressure carbon dioxide $\left(\mathrm{PET}_{\mathrm{CO} 2}\right)$ and end-tidal pressure oxygen $\left(\mathrm{PET}_{\mathrm{O} 2}\right)$ for cerebrovascular response to an euoxic hypercapnia test. Control of desired $\mathrm{PET}_{\mathrm{CO} 2}$ and $\mathrm{PET}_{\mathrm{O} 2}$ values is achieved accurately and continuously using sophisticated software (BreatheM v2.40, University Laboratory of Physiology, Oxford, UK) and dynamic end-tidal forcing technique as previously described [43,44]. The test lasts 17 minutes with two 3-minute steps of carbon dioxide. For the first minute, participants breathe room air only. This time period is followed by a five-minute baseline period in which the PET $_{\mathrm{CO} 2}$ is held at $+1.0 \mathrm{mmHg}$ above the participants' resting $\mathrm{PET}_{\mathrm{CO} 2}$ value. Following baseline, $\mathrm{PET}_{\mathrm{CO} 2}$ is increased to $+5.0 \mathrm{mmHg}$ above normal resting values and held for three minutes and then is increased to $+8.0 \mathrm{mmHg}$ and is again held for three minutes. Lastly, $\mathrm{PET}_{\mathrm{CO} 2}$ is dropped back down to $+1.0 \mathrm{mmHg}$ above resting values and held for the final five minutes of the test.

Following the hypercapnia test, participants rest for 20-30 minutes. Then, participants are seated on the recumbent cycle ergometer and cerebrovascular response to submaximal exercise is assessed. This test lasts 30 minutes during which participants complete two six-minute intervals of exercise as previously described [12].

Assessment of cognition, mood, sleep, and social support Participants undergo cognitive testing four times, at six month intervals, during the course of the study (see

Table 3 BIM neuropsychological assessment

\begin{tabular}{ll}
\hline Domain & Test \\
\hline Attention & Attention Network Test [51-53] \\
& Auditory Consonant Trigram Test [54] \\
Processing Speed & Symbol-Digit Modalities [55] \\
Verbal Memory & Buschke Selective Reminding Test [56,57]
\end{tabular}

Visual Memory Medical College of Georgia Complex Figures Test (MCG) [58]

Executive Delis-Kaplan Executive Function System Function (D-KEFS) [59]

\section{Description}

Computerized test of the efficiency of 3 attention networks, including tests of altering, orienting and executive control (flanker test)

Auditory presentation of 3 consonant trigrams (i.e., three single consonant letters) followed by a number. The subject is instructed to subtract from that number for several seconds until cued, and then asked to recall the letters

Simple substitution task pairing specific numbers with given geometric figures. Both written ( 90 seconds) and oral (90 seconds) forms administered

1. Memory Test (List learning of 12 words rehearsed for six trials)

2. Cued Recall

3. Multiple Choice recognition

4. Oral delayed recall of 12 words (30 minutes following multiple choice)

A test of visual memory in which the subject is asked to copy the figure and then draws it from memory at an immediate test and at a 30 minute delay

1. Card Sorting Test- one card set is randomly assigned to each session (i.e., one card set per phase) in which the free-sorting and recognition conditions are tested

2. Color-word Interference Test- four conditions are presented to participants (i.e., colour naming, word reading, inhibition, and inhibition/switching) and participants must follow the presented rule to orally complete the task as accurately as possible

3. Verbal Fluency Test- participants must say as many words as possible in 60 seconds for each condition (i.e., letter fluency, category fluency, and category switching)

61 different rare words are presented with scoring based on American and Canadian punctuation rules

65 adjectives are presented that are rated by subjects using a 5-point scale. From the responses 6 factors are derived (tension-anxiety, vigour-activity, depressiondejection, fatigue-inertia, anger-hostility, and confusion-bewilderment

Self-report questionnaire of the last month sleep habits/sleep quality

Self-report of general daytime sleepiness

Self-report questionnaire of perceived social support from family, friends, and other study participants

20 questions that assess cognitive activities participants were engaged in during childhood (age 6), teens (age 12), young adults (age 18), and adulthood (age 40)

23 questions that assess the degree to which participants are cognitively active in their lives at the present time 
Table 3 for details of the specific standardized and experimental tests done). The tests were chosen to assess cognitive domains that had previously been shown to be affected by fitness training, with a special focus on executive functions, processing speed, and memory $[21,27,45]$. In addition, we will look for changes in mood [46] and sleep $[47,48]$ using validated self-report questionnaires. Involvement in the study might modify the perception by participants of their observed social support (i.e., the feeling that one is care for, has assistance available from other people, and that one is part of a supportive social network). As higher levels of perceived social support could increase adherence to the exercise program and have an independent beneficial impact on both mental and physical health (see [49] for review and discussion), perceived social support will be measured during the course of the study by a modified version of the Lubben Social Network Scale [50]. The testing sessions lasts approximately 120 minutes with short breaks taken as necessary. The same testing order is maintained through all assessments during the study.

\section{Questionnaires}

\section{Physical activity questionnaires}

At Pre-intervention Phase Test $1 B$ participants complete the interviewer-administered Lifetime Physical Activity Questionnaire to quantify lifetime occupational, household, and exercise/sports activities and used to determine lifetime physical activity patterns [31]. The Past Year Physical Activity Questionnaire [33] is self-reported and given to participants immediately following the completion of the exercise intervention, which assesses physical activities while enrolled in the BIM study. At the completion of the study (Post-intervention Phase 3), participants are given the Past Six Month Physical Activity Questionnaire to assess their activity level six-months following completion of the exercise intervention.

\section{Diet history questionnaire}

The Diet History Questionnaire (DHQ) is a selfadministered food frequency questionnaire originally designed by the National Cancer Institute but modified for use in Canada [30]. Consisting of 146 questions about 124 different food items, the questionnaire includes questions about portion size, seasonal intake, and fat usage within the past 12 months [30]. Participants complete the questionnaire at enrollment into the study and following the completion of the exercise intervention.

\section{Statistical analysis}

The primary outcome measure is the change in overall cognitive function (defined as the average of standardized cognitive domain scores) over time. The sample size estimates assume a two-tailed alpha level of 0.05 , power of
90\% $(\beta=0.1)$ and a change in overall cognitive score of 0.2 standard deviation units based on Brown et al. [12]. To account for a predicted $15 \%$ dropout rate to account for withdrawals [63] and non-compliance with the exercise sessions (i.e., attendance $85 \%$ or less of all sessions), we will recruit 125 men and 125 women $(n=250)$. The primary outcome analysis within individuals will use repeated measures analysis of variance using a general linear mixed model. Cardiorespiratory fitness, vascular measurements of resting $\mathrm{CBF}$, cerebrovascular reserve, cerebrovascular conductance, mood and sleep are secondary outcome measures. The covariates being considered in our analysis include age, sex, education, socio-economic status, BMI, hormones, lipids profiles, genetics, diet, physical activity and physical fitness (i.e. $\mathrm{VO}_{2} \mathrm{max}$ ). Multivariable methods will be used to determine if covariates are predictors of our primary outcome measure (overall cognition) [12].

\section{Discussion}

Current projections suggest that by 2031, approximately $25 \%$ of the Canadian population will be over the age of 65 [7] and in 2050, the estimated world population over the age of 60 will be 2 billion [3]. With societal aging, a progressive increase in the absolute number of individuals suffering from age-associated health issues like cerebrovascular disease, $\mathrm{VaD}$, and $\mathrm{AD}$ will inevitably occur unless we can change the likelihood of these events occurring. If we cannot, population aging will lead to a significantly greater burden on the health and social care system of our country and around the world. Effective prevention of these diseases is of paramount importance. A promising approach is encouraging higher levels of physical activity since exercise may delay or prevent the progression of cognitive decline associated with aging, prevent cerebrovascular disease, and delay the onset of AD and related dementias [64].

The BIM study is designed to add to the literature on whether exercise can be an effective means of decreasing the effects of aging on cognition. This study will combine detailed physiological and cognitive data with sociodemographic, biologic, and lifestyle information obtained from a relatively large and well defined older population. By performing an exercise intervention we are able to investigate the extent to which cerebrovascular physiology might act as a mediating factor between exercise and cognition. If confirmed this raises the possibility of cerebrovascular measures functioning as a surrogate marker of brain health in future studies of exercise interventions.

The BIM study uses state-of-the-art measurements of cerebrovascular function, physical fitness, cognitive function, lifestyle, sleep, biologic, and genetic markers all of which strengthen the study. The Laboratory for Human Cerebrovascular Physiology houses sophisticated equipment to control end-tidal $\mathrm{PO}_{2}$ and $\mathrm{PCO}_{2}$ accurately and 
continuously using our dynamic forcing-function system. The $\mathrm{VO}_{2}$ max testing protocols used in the study are considered the "gold-standard" practice for the assessment of physical fitness, thereby adding strength to the study since we avoid problems associated with predictive tests by measuring $\mathrm{VO}_{2}$ max rather than $\mathrm{VO}_{2}$ peak [65]. The comprehensive neuropsychological test battery allows us to assess multiple aspects of cognitive function. The battery is administered at multiple time points through the study that will allow the assessment of whether the exercise intervention has an impact on cognitive function, how long it takes to become evident, and its duration. We have included numerous selfadministered questionnaires to measure changes in dietary intake, sleep habits, physical activity levels and cognitive abilities at differing time points. Collectively, these data will provide insights regarding the possible mechanisms whereby exercise improves cerebrovascular and cognitive function.

The current study is unique because all the participants of our study attend our supervised and structured exercise program for six-months. Further, the exercise program is individually tailored to each participant as exercise prescriptions are based on each individual's heart rate reserve. This supervised intervention assesses participants' progression through the exercise program with modifications to the intervention made as needed. The BIM study uses a quasi-experimental prospective cohort design because it reduces variability over time since each participant is their own control during the repeated baseline assessment over a six-month period. An inherent weakness is the potential carry over or practice effects in repeated cognitive testing. We have attempted to deal with this issue by 1) repeating the baseline cognitive testing to observe the stability of the performance measures over time before the intervention, 2) using alternate forms of tests when possible (i.e., verbal fluency, selective reminding, MCG figure, card sorting), and 3) we will analyze the cognitive data for overall trends at the four time points to examine for a global practice effect over time. The next logical step in our research program will be a randomized controlled trial in first a healthy and then in a diseased population (e.g. individuals with Mild Cognitive Impairment or stroke).

The mechanisms whereby exercise-induced increases in cerebrovascular reserve improve cognitive function are unknown. At this time, we are focused on demonstrating the physiologic mechanisms by which exercise confers its beneficial influence on cognition. The BIM study is the first to examine the influence of an aerobic exercise intervention on cerebrovascular and cognitive function in a healthy aging population. The results from this study may inform the development of new therapies to reduce or prevent the cognitive decline associated with aging.

\section{Abbreviations}

AD: Alzheimer's disease; CBF: Cerebral blood flow; BIM: Brain in motion; BMI: Body mass index; MoCA: Montreal cognitive assessment; $\mathrm{VO}_{2}$ max: Maximal aerobic capacity; HRR: Heart rate reserve; RER: Respiratory exchange ratio; ECG: Electrocardiogram; MCA: Middle cerebral artery; PO2: Endtidal oxygen; PCO2: Endtidal carbon dioxide; TCD: Transcranial doppler ultrasound; VaD: Vascular dementia; $\bar{V} P$ : Peak velocity; $\bar{V} I W M$ : Intensity-weighted mean; $\bar{P}$ : Power; $\mathrm{PET}_{\mathrm{CO} 2}$ : End-tidal pressure carbon dioxide; PET 2 : End-tidal pressure oxygen; D-KEFS: Delis-kaplan executive function system; MCG: Medical college of georgia complex figure; DHQ: Diet history questionnaire.

\section{Competing interests}

The authors declare that they have no competing interests.

\section{Authors' contributions}

GAE, CMF, MDH, DBH, RSL, TJA, RL, EES, MJP have made substantial contributions to conception and design of this study. AVT and MHD wrote the draft of the manuscript and all authors were involved in revising the manuscript critically for important intellectual content. BJW provided significant medical coverage for exercise testing. GMB and EH were involved in coordinating the study and recruitment. GAL contributed the social support questionnaire to the study. All authors have given final approval of the version to be published.

\section{Acknowledgements}

The present study is supported by the Canadian Institutes of Health Research operating grant (735144; MJP (Principal Applicant), GAE, CMF, MDH, DBH, RSL (Co-Applicants), TJA, RL and EES (Collaborators)), Alzheimer Society Research Program doctoral award (AVT), Heart and Stroke Foundation of CanadaFocus on Stroke Postdoctoral fellowship (MHD), Alberta Innovates-Health Solutions (MJP, MDH (Senior Scholar), CMF (Health Senior Scholar), GAE (Visiting Scientist), GAL (Postgraduate Fellowship)), Heart \& Stroke Foundation Visiting Scientist (GAE), The Brenda Stafford Foundation Chair in Geriatric Medicine of the University of Calgary (DBH), The Brenda Strafford Foundation (DBH, MJP), Heart \& Stroke Foundation of Alberta, NWT and Nunavut (MDH), and the Alberta Cancer Foundation Weekend to End Breast Cancer Chair (CMF). We thank Polar ${ }^{\circledR}$ for their support and contribution of the heart rate monitoring equipment and the Team ${ }^{2}$ system used during the exercise intervention sessions. We also thank the Dean (Dr. Wayne Giles (2006-2012)) and the Faculty of Kinesiology for the support in facilitating the exercise intervention. We thank Brad Hansen (technical support), Kristin Sabourin (physiological and exercise testing), and Jacqueline Harrison (physiological testing and data analysis) in Dr. Marc Poulin's Laboratory of Human

Cerebrovascular Physiology for their assistance in testing. We also thank Dr. Stephen Wilton and Dr. Billie-Jean Martin for providing medical coverage for exercise testing.

\section{Author details}

'Department of Physiology \& Pharmacology, Faculty of Medicine, University of Calgary, Calgary, Alberta T2N 4N1, Canada. ${ }^{2}$ Hotchkiss Brain Institute, Faculty of Medicine, University of Calgary, Calgary, Alberta T2N 4N1, Canada. ${ }^{3}$ Department of Medicine, Faculty of Medicine, University of Calgary, Calgary, Alberta T2N 4N1, Canada. ${ }^{4}$ Department of Clinical Neurosciences, Faculty of Medicine, University of Calgary, Calgary, Alberta T2N 4N1, Canada.

${ }^{5}$ Department of Psychiatry, Faculty of Medicine, Dalhousie University, Halifax, Nova Scotia B3H 2E2, Canada. ${ }^{6}$ Department of Psychology, Faculty of Science, Dalhousie University, Halifax, Nova Scotia B3H 4R2, Canada. ${ }^{7}$ Department of Medicine (Neurology), Dalhousie University, Halifax, Nova Scotia B3H 3A7, Canada. ${ }^{8}$ Department of Population Health Research, Alberta Health Services-Cancer Care, Calgary, Alberta T2S 3C3, Canada. ${ }^{9}$ Department of Oncology, Faculty of Medicine, University of Calgary, Calgary, Alberta T2N 4N1, Canada. ${ }^{10}$ Department of Community Health Sciences, Faculty of Medicine, Faculty of Medicine, University of Calgary, Calgary, Alberta T2N 4N1, Canada. ${ }^{11}$ Faculty of Kinesiology, University of Calgary, Calgary, Alberta T2N 1N4, Canada. ${ }^{12}$ Department of Radiology, Faculty of Medicine, University of Calgary, Calgary, Alberta T2N 4N1, Canada. ${ }^{13}$ Brenda Stafford Foundation Chair in Geriatric Medicine, Faculty of Medicine, University of Calgary, Calgary, Alberta T2N 4N1, Canada. ${ }^{14}$ Psychology Service, Alberta Health Services, Foothills Hospital, Calgary, Alberta T2N 2T9, Canada. ${ }^{15}$ University of Calgary, Calgary, Alberta T2N 4N1, Canada. ${ }^{16}$ Department of Cardiac Science, 
Faculty of Medicine, University of Calgary, Calgary, Alberta T2N 4N1, Canada.

${ }^{17}$ Airway Inflammation Research Group, Faculty of Medicine, University of Calgary, Calgary, Alberta T2N 4N1, Canada. ${ }^{18}$ Snyder Institute for Chronic Diseases, Faculty of Medicine, University of Calgary, Calgary, Alberta T2N 4N1, Canada.

Received: 31 January 2013 Accepted: 21 February 2013

Published: 28 February 2013

\section{References}

1. Middleton LE, Barnes DE, Lui L, Yaffe K: Physical activity over the life course and its association with cognitive performance and impairment in old age. J Am Geriatr Soc 2010, 58(7):1322-1326.

2. Public Health Agency of Canada- Physical Activity and Older Adults. http:// publications.gc.ca/collections/Collection/H88-4-1999E.pdf.

3. Dementia: A Public Health Priority. http://whqlibdoc.who.int/publications/ 2012/9789241564458 eng.pdf.

4. Canada's Physical Activity Guide to Healthy Active Living for Older Adults. http://www.alcoa.ca/e/projects/canguide.htm.

5. Gorelick PB, Sacco RL, Smith DB, Alberts M, Mustone-Alexander L, Rader D, Ross JL, Raps E, Ozer MN, Brass LM, Malone ME, Goldberg S, Booss J, Hanley DF, Toole JF, Greengold NL, Rhew DC: Prevention of a first stroke: a review of guidelines and a multidisciplinary consensus statement from the national stroke association. J Am Med Assoc 1999, 281(12):1112-1120

6. Laurin D, Verreault R, Lindsay J, MacPherson K, Rockwood K: Physical activity and risk of cognitive impairment and dementia in elderly persons. Arch Neurol 2001, 58(3):498-504.

7. Statistics Canada 2010- Population projections: Canada, the provinces and territories (2009-2036). http://www.statcan.gc.ca/pub/91-520-x/91-520x2010001-eng.pdf.

8. Bishop NA, Lu T, Yankner BA: Neural mechanisms of ageing and cognitive decline. Nature 2010, 464(7288):529-535.

9. Grady C: The cognitive neuroscience of ageing. Nat Rev Neurosci 2012, 13(7):491-505.

10. Albert MS, DeKosky ST, Dickson D, Dubois B, Feldman HH, Fox NC, Gamst A, Holtzman DM, Jagust WJ, Petersen RC, Snyder PJ, Carrillo MC, Thies B, Phelps $\mathrm{CH}$ : The diagnosis of mild cognitive impairment due to Alzheimer's disease: recommendations from the national institute on aging-Alzheimer's association workgroups on diagnostic guidelines for Alzheimer's disease. Alzheimers Dement 2011, 7(3):270-279.

11. Silvestrini M, Pasqualetti $P$, Baruffaldi $R$, Bartolini M, Handouk $Y$, Matteis $M$, Moffa F, Provinciali L, Vernieri F: Cerebrovascular reactivity and cognitive decline in patients with Alzheimer disease. Stroke 2006, 37(4):1010-1015.

12. Brown AD, McMorris CA, Longman RS, Leigh R, Hill MD, Friedenreich CM, Poulin MJ: Effects of cardiorespiratory fitness and cerebral blood flow on cognitive outcomes in older women. Neurobiol Aging 2010, 31(12):2047-2057.

13. Riecker A, Grodd W, Klose U, Schulz JB, Gröschel K, Erb M, Ackermann H, Kastrup A: Relation between regional functional MRI activation and vascular reactivity to carbon dioxide during normal aging. $J$ Cereb Blood Flow Metab 2003, 23(5):565-573.

14. Grolimund P, Seiler RW: Age dependence of the flow velocity in the basal cerebral arteries - a transcranial Doppler ultrasound study. Ultrasound Med Biol 1988, 14(3):191-198.

15. Davenport MH, Hogan DB, Eskes GA, Longman RS, Poulin MJ: Cerebrovascular reserve: the link between fitness and cognitive function? Exerc Sport Sci Rev 2012, 40(3):153-158.

16. Cunnane S, Nugent S, Roy M, Courchesne-Loyer A, Croteau E, Tremblay S, Castellano A, Pifferi F, Bocti C, Paquet N, Begdouri H, Bentourkia M, Turcotte E, Allard M, Barberger-Gateau P, Fulop T, Rapoport SI: Brain fuel metabolism, aging, and Alzheimer's disease. Nutrition 2011, 27(1):3-20.

17. Iadecola C: Neurovascular regulation in the normal brain and in Alzheimer's disease. Nat Rev Neurosci 2004, 5(5):347-360.

18. Girouard $\mathrm{H}$, ladecola C: Neurovascular coupling in the normal brain and in hypertension, stroke, and Alzheimer disease. J Appl Physiol 2006, 100(1):328-335.

19. Attwell $D$, ladecola $C$ : The neural basis of functional brain imaging signals. Trends Neurosci 2002, 25(12):621-625.

20. Ahlskog JE, Geda YE, Graff-Radford NR, Petersen RC: Physical exercise as a preventive or disease-modifying treatment of dementia and brain aging. Mayo Clin Proc 2011, 86(9):876-884
21. Eskes GA, Longman S, Brown AD, McMorris CA, Langdon KD, Hogan DB, Poulin M: Contribution of physical fitness, cerebrovascular reserve and cognitive stimulation to cognitive function in postmenopausal women. Front Aging Neurosci 2010, 2:1-7.

22. Voss MW, Nagamatsu LS, Liu-Ambrose T, Kramer AF: Exercise, brain, and cognition across the life span. J Appl Physiol 2011, 111(5):1505-1513.

23. Erickson KI, Voss MW, Prakash RS, Basak C, Szabo A, Chaddock L, Kim JS, Heo S, Alves H, White SM, Wojcicki TR, Mailey E, Vieira VJ, Martin SA, Pence BD, Woods JA, McAuley E, Kramer AF: Exercise training increases size of hippocampus and improves memory. Proc Natl Acad Sci U S A 2011, 108(7):3017-3022.

24. Colcombe SJ, Erickson KI, Scalf PE, Kim JS, Prakash R, McAuley E, Elavsky S, Marquez DX, Hu L, Kramer AF: Aerobic exercise training increases brain volume in aging humans. J Gerontol A Biol Sci Med Sci 2006, 61(11):1166-1170.

25. Burns JM, Cronk BB, Anderson HS, Donnelly JE, Thomas GP, Harsha A, Brooks WM, Swerdlow RH: Cardiorespiratory fitness and brain atrophy in early Alzheimer disease. Neurology 2008, 71(3):210-216.

26. Middleton $L E$, Yaffe K: Promising strategies for the prevention of dementia. Arch Neurol 2009, 66(10):1210-1215.

27. Churchill JD, Galvez R, Colcombe S, Swain RA, Kramer AF, Greenough WT: Exercise, experience and the aging brain. Neurobiol Aging 2002, 23(5):941-955.

28. Ainslie PN, Cotter JD, George KP, Lucas S, Murrell C, Shave R, Thomas KN Williams MJA, Atkinson G: Elevation in cerebral blood flow velocity with aerobic fitness throughout healthy human ageing. J Physiol (Lond ) 2008, 586(16):4005-4010.

29. Rossetti HC, Lacritz LH, Munro Cullum C, Weiner MF: Normative data for the Montreal cognitive assessment (MoCA) in a population-based sample. Neurology 2011, 77(13):1272-1275.

30. Csizmadi I, Kahle L, Ullman R, Dawe U, Zimmerman TP, Friedenreich CM, Bryant $\mathrm{H}$, Subar AF: Adaptation and evaluation of the national cancer Institute's diet history questionnaire and nutrient database for Canadian populations. Public Health Nutr 2007, 10(1):88-96.

31. Friedenreich CM, Courneya KS, Bryant HE: The lifetime total physical activity questionnaire: development and reliability. Med Sci Sports Exerc 1998, 30(2):266-274.

32. American College of Sports Medicine, Thompson WR, Gordon NF, Pescatello LS: ASCM's quidelines for exercise testing and prescription. 8th edition. Philadelphia: Lippincott Williams \& Wilkins; 2010.

33. Friedenreich CM, Courneya KS, Neilson HK, Matthews $C E$, Willis G, Irwin M, Troiano R, Ballard-Barbash R: Reliability and validity of the past year total physical activity questionnaire. Am J Epidemiol 2006, 163(10):959-970.

34. Pialoux V, Brown AD, Leigh R, Friedenreich CM, Poulin MJ: Effect of cardiorespiratory fitness on vascular regulation and oxidative stress in postmenopausal women. Hypertension 2009, 54(5):1014-1020.

35. Barnett $\mathrm{JH}$, Jones PB, Muller U, Robbins TW: Effects of the catechol-O -methyltransferase Val.sup.158]Met polymorphism on executive function: a meta-analysis of the Wisconsin Card Sort Test in schizophrenia and healthy controls. Mol Psychiatry 2007, 12:502+.

36. Strittmatter WJ, Saunders AM, Schmechel D, Pericak-Vance M, Enghild J, Salvesen GS, Roses AD: Apolipoprotein E: High-avidity binding to $\beta$ amyloid and increased frequency of type 4 allele in late-onset familial Alzheimer disease. Proc Natl Acad Sci U S A 1993, 90(5):1977-1981.

37. Vaynman S, Ying Z, Gomez-Pinilla F: Hippocampal BDNF mediates the efficacy of exercise on synaptic plasticity and cognition. Eur J Neurosci 2004, 20(10):2580-2590.

38. Latimer CS, Searcy JL, Bridges MT, Brewer LD, Popović J, Blalock EM, Landfield PW, Thibault O, Porter NM: Reversal of glial and neurovascular markers of unhealthy brain aging by exercise in middle-aged female mice. PloS One 2011, 6(10):e26812.

39. Paterson DH, Cunningham DA, Koval JJ, St. Croix CM: Aerobic fitness in a population of independently living men and women aged 55-86 years. Med Sci Sports Exerc 1999, 31(12):1813-1820.

40. Canadian Society for Exercise Physiology: Professional Fitness and Lifestyle Consultant: Resource Manual, Canadian Society for Exercise Physiology. Ottawa: Canadian Society for Exercise Physiology; 1996.

41. Anonymous: ATS/ACCP Statement on cardiopulmonary exercise testing. Am J Respir Crit Care Med 2003, 167(2):211-277.

42. Aaslid R, Markwalder TM, Nornes H: Noninvasive transcranial Doppler ultrasound recording of flow velocity in basal cerebral arteries. J Neurosurg 1982, 57(6):769-774. 
43. Poulin MJ, Liang P, Robbins PA: Dynamics of the cerebral blood flow response to step changes in end- tidal PCO2 and PO2 in humans. J Appl Physiol 1996, 81(3):1084-1095.

44. Lambertsen CJ: Invited Editorial on 'Fast and slow components of cerebral blood flow response to step decreases in end-tidal PCO2 in humans'. J Appl Physiol 1998, 85(2):386-387.

45. Colcombe S, Kramer AF: Fitness effects on the cognitive function of older adults: a meta-analytic study. Psychol Sci 2003, 14(2):125-130.

46. McNair D, Lorr M, Droppleman L: Profile of Mood States. San Diego, CA: Educational and Industrial Testing Service; 1981.

47. Buysse DJ, Reynolds CF III, Monk TH, Berman SR, Kupfer DJ: The Pittsburgh sleep quality index: a new instrument for psychiatric practice and research. Psychiatry Res 1989, 28(2):193-213.

48. Johns MW: A new method for measuring daytime sleepiness: the Epworth sleepiness scale. Sleep 1991, 14(6):540-545.

49. Kremen WS, Lachman ME, Pruessner JC, Sliwinski M, Wilson RS: Mechanisms of age-related cognitive change and targets for intervention: social interactions and stress. J Gerontol A Biol Sci Med Sci 2012, 67 A(7):760-765.

50. Lubben J, Blozik E, Gillmann G, liffe S, Von Kruse WR, Beck JC, Stuck AE: Performance of an abbreviated version of the lubben social network scale among three European community-dwelling older adult populations. Gerontologist 2006, 46(4):503-513.

51. Fan J, McCandliss BD, Sommer T, Raz A, Posner MI: Testing the efficiency and independence of attentional networks. J Cogn Neurosci 2002, 14(3):340-347.

52. Callejas A, Lupiànez J, Funes MJ, Tudela P: Modulations among the alerting, orienting and executive control networks. Exp Brain Res 2005, 167(1):27-37.

53. Posner MI, Petersen SE: The attentional system of the human brain. Annu Rev Neurosci 1990, 13:25-42.

54. Stuss DT, Stethem LL, Poirier CA: Comparison of three tests of attention and rapid information processing across six age groups. Clin Neuropsychol 1987, 1(2):139-152.

55. Lezak M: Neuropsychological Assessment. New York: Oxford University Press; 2004.

56. Buschke H, Altman Fuld P: Evaluating storage, retention and retrieval in disordered memory and learning. Neurology 1974, 24(11):1019-1025.

57. Hannay HJ, Levin HS: Selective reminding test: an examination of the equivalence of four forms. J Clin Exp Neuropsychol 1985, 7(3):251-263.

58. Meador KJ, Moore EE, Nichols ME, Abney OL, Taylor HS, Zamrini EY, Loring DW: The role of cholinergic systems in visuospatial processing and memory. J Clin Exp Neuropsychol 1993, 15(5):832-842.

59. Delis DC, Kaplan E, Kramer JH: Delis Kaplan Executive Functioning System (D-KEFS). San Antonio: NCS Pearson, Inc; 2001.

60. Uttl B: North American adult reading test: Age norms, reliability, and validity. J Clin Exp Neuropsychol 2002, 24(8):1123-1137.

61. Nyenhuis DL, Yamamoto C, Lucheta T, Terrien A, Parmentier A: Adult and geriatric normative data and validation of the profile of mood states. J Clin Psychol 1999, 55(1):79-86.

62. Wilson RS, Bennett DA, Beckett LA, Morris MC, Gilley DW, Bienias JL, Scherr $P A$, Evans DA: Cognitive activity in older persons from a geographically defined population. J Gerontol B Psychol Sci Soc Sci 1999, 54(3):P155-P160

63. Deley G, Kervio G, Van Hoecke J, Verges B, Grassi B, Casillas J: Effects of a one-year exercise training program in adults over 70 years old: a study with a control group. Aging Clin Exp Res 2007, 19(4):310-315.

64. Lautenschlager NT, Cox KL, Flicker L, Foster JK, Van Bockxmeer FM, Xiao J, Greenop KR, Almeida OP: Effect of physical activity on cognitive function in older adults at risk for Alzheimer disease: a randomized trial. JAMA 2008, 300(9):1027-1037.

65. Per-Olof êAstrand, Rodahl K: From evaluation of physical performance on the basis of tests, Textbook of Work Physiology: Physiological Bases of Exercise. Volume 4. McGraw-Hill; 2003:273-299.

doi:10.1186/1471-2318-13-21

Cite this article as: Tyndall et al:: The brain-in-motion study: effect of a 6-month aerobic exercise intervention on cerebrovascular regulation and cognitive function in older adults. BMC Geriatrics 2013 13:21.

\section{Submit your next manuscript to BioMed Central and take full advantage of:}

- Convenient online submission

- Thorough peer review

- No space constraints or color figure charges

- Immediate publication on acceptance

- Inclusion in PubMed, CAS, Scopus and Google Scholar

- Research which is freely available for redistribution

Submit your manuscript at www.biomedcentral.com/submit
C Biomed Central 